\title{
Assessment of tempromandibular joint space and condylar position in patients with myofacial pain dysfunction syndromes by using cone beam computed tomography
}

Accepted: $26 / 6 / 2014$

\begin{abstract}
Hassan Ali Mahmood * Katayon Nathm Kurshid ** Sarkawt Hamad Ali * Sangar Hamid Ali ***
\section{Abstract}

Background and objective: Joint space assessment and condylar relation in the glenoid fossa is considered as integral component of the clinical assessment of the patient with tempromandibular joint disorder. Any variant from normal tempromandibular joint may affect the diagnosis and management of the case.

Methods: Thirty patients with unilateral myofacial pain dysfunction syndrome were included in this study (14 male and 16 female). Joint space analysis was performed by cone beam computed tomography for all patients. Analysis of data for joint spaces (anterior, middle, posterior, medial and lateral) was performed by using t-test.

Results: The joint spaces and condyle positions in anterior, superior and posterior regions showed less joint space and statistically significant difference $(P<0.05)$ from same joint space of normal side. No statistically significant differences were found in space value between middle and lateral condylar space of the diseased side and normal side of the patient. The joint spaces in normal sides were between 2 to $3.2 \mathrm{~mm}$. Age and gender variations showed no statistical differences.

Conclusion: The use of cone beam computed tomography for examination of tempromandibular joint space in patients with myofacial pain dysfunction syndrome give a good diagnostic criteria for affected side.

Keywords: Cone beam computed tomography, Joint space, myofacial pain dysfunction syndrome, tempromandibular joint.
\end{abstract}

\section{Introduction}

Temporomandibular joint (TMJ) disorder can cause various combination of limitation of movement of the jaw, pain and joint sounds. Many etiological factors play a role in developing TMJ disease like trauma, inflammatory and degenerative disease, emotional stress, abnormal habit and others causes. The source of pain and restriction of mouth opening usually arise from masticatory muscle or from joint structures in TMJ disorder. Joint space is radiographic term for the crescent shaped radiolucency between the bony structures of the TMJ when the teeth are in occlusion. $^{1-3}$ Many studies showed that muscle spasm play important role in pain of TMJ area. ${ }^{2-6}$ The analysis of the TMJ space appears to be important in the study of TMJ disorder since a reduction of the joint space can be caused by compressive loading of the visco elastic TMJ disc..$^{7-9}$ The amount of joint space and condylar position in patient with myofacial pain dysfunction syndrome may show some variation from normal cases, as this area still need more investigation to define this relation between Joint space condylar position and myofacial pain. ${ }^{10-13}$ Many studies define the glenoid fossa radiogrphically either by ortho pantomo graph (OPG), CT scan, cone beam computed tomography (CBCT) ${ }^{12,14-19}$ Different studies indicated that the analysis of joint space and condylar position is best done by using CBCT which can provide

* Department of oral diagnosis, college of dentistry, Hawler medical university, Erbil, Iraq.

** Department of surgery, college of medicine, Hawler medical university, Erbil, Iraq.

*** Specialized Dental Polyclinic, Directorate of Health, Erbil, Iraq. 
reconstructed images of high diagnostic quality with lower radiation doses as high resolution where compared to the normal CT. ${ }^{11,12,14,15}$ The aim of this study was to analyze TMJ space in patients with myofacial pain dysfunction syndrome.

\section{Methods}

Study group: Thirty patients were included in this study (14 males and 16 female) with their age ranging from 18to 60 years. These patients were selected from the Teaching poly clinic of the College of Dentistry in Hawler Medical University and a private dental poly clinic in Erbil city. Patients who had TMJ myofacial pain dysfunction syndrome in one side only were included in this study. History and clinical examination were done for these patients to determine the type of joint pain and radiographic examination (TMJ view) by CBCT was done for all cases after explaining the procedure to the patient and obtaining patient consent for participation.

Types of participants: Patients having myofacial pain of different degrees of severity were included in this study. The diagnostic criteria of myofacial pain were made if the following sign and symptoms were present:

1- Pain on palpation of the temporomandibular joint.

2- Pain on palpation of associated mandibular muscles.

3- Limitation and deviation of mandibular movement.

4- Joint sounds and headache.

Headache alone or joint sound alone is not diagnostic of myofacial pain. ${ }^{13}$

\section{Inclusion criteria}

1- Patients having pain and clicking, crepitation (joint sound) with/or without limitation of mouth opening.

2- Patient with normal CBCT morphology of condylar head and glenoid fossa and having no signs of any degenerative disease or inflammatory bong changes like arthritis.

3- No history of arthritis, diabetes mellitus, osteoarthritis or other bone disease.
CBCT scan examination: New Tom

Giano cone beam 3D imaging (Italy)

was used with the following scanning

parameters for all patients:

Local spot; $0.5 \mathrm{~mm}$

Scan time; $18 \mathrm{~s}$

x-ray emission time; $3.6-6.7 \mathrm{~s}$

effective dose; ICRP 103 (msv)

software; NNTTM with free viewer

Measurements:

Axial slice through condylar heads was done to show the thickness of condyle head in midiolateral direction as shown in Figure 1 cut within $1 \mathrm{~mm}$ thickness was done. The second axial slice was done on condylar head in sagittal direction to show anterior, superior and posterior joint spaces. The methods of measurement of joint spaces where same methods of Zahra. ${ }^{14}$ For measuring the joint spaces, the middle condylar slice selected in both axial section of condyle space measurement in other views. In the sagittal view a line was drawn horizontally on upper most area of the glenoid fossa and the intersection of this line with the glenoid fossa was selected as superior reference point. From this point a line was drawn to contact the most anterior and posterior condylar bone, as shown in Figure 1. From these two contact points a perpendicular line was drawn on these tangential lines till it contact the glenoid fossa in anterior posterior joined space were taken as joint spaces. For measuring the joint spaces in the superior, middle and lateral of condylar head region, true coronal view was selected and a line drawn from deepest point of glenoid fossa, and two tangential lines were drawn on medial of lateral side of condylar bone and a perpendicular line drawn from medial and lateral tangents from contact point till it contacts with the glenoid fossa which is consider as medial and lateral joined space as shown in Figure 2. A perpendicular line was drawn between two lines from glenoid fossa to the head of condylar which is considered as superior joint space. 
Statistical analyses: All data were included analyses of variance (t-test) expressed as means \pm standard error (SE) and statistical analysis was carried out using statistical package for the social sciences (version 18). Data analysis to compare between anterior, middle, posterior, medial and lateral TMJ spaces of disease and normal side of the patient.
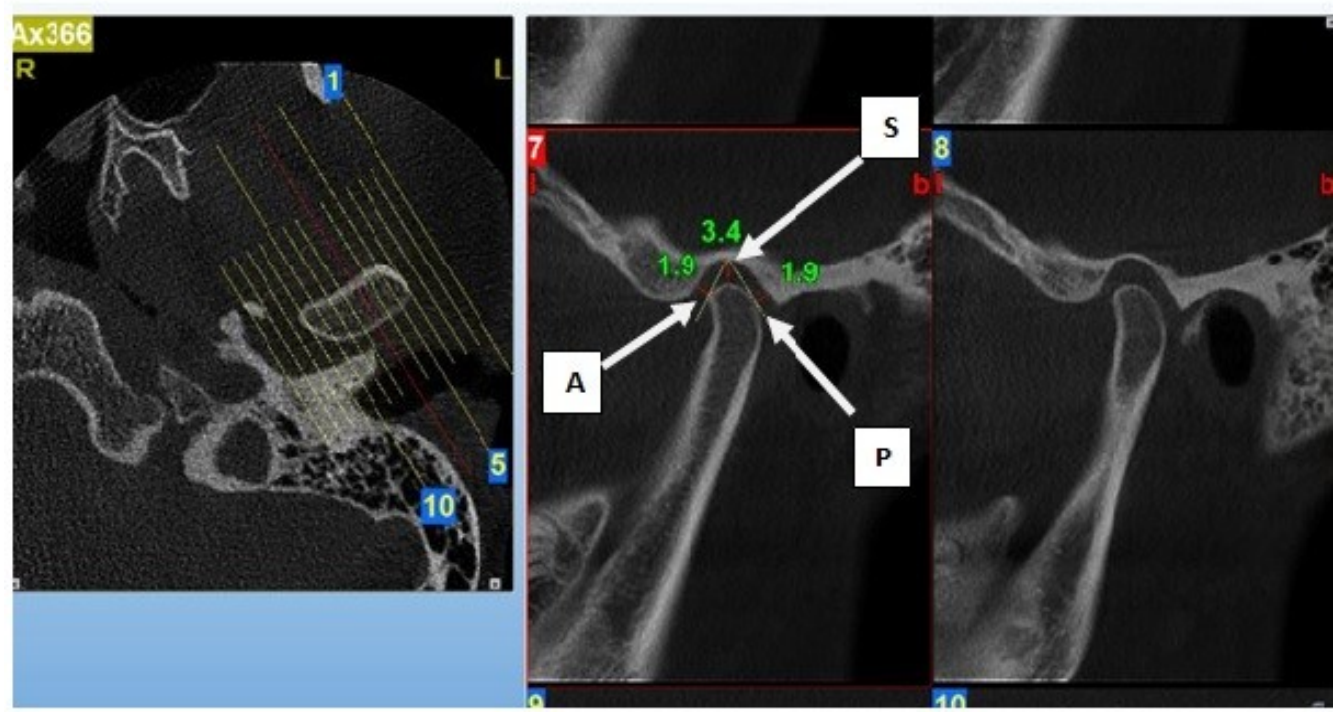

Figure 1: The measurement of joint spaces around condylar head in $\mathrm{mm}$ distance by CBCT, Anterior joint space (A), Superior joint space (S) and Posterior joint space (P).

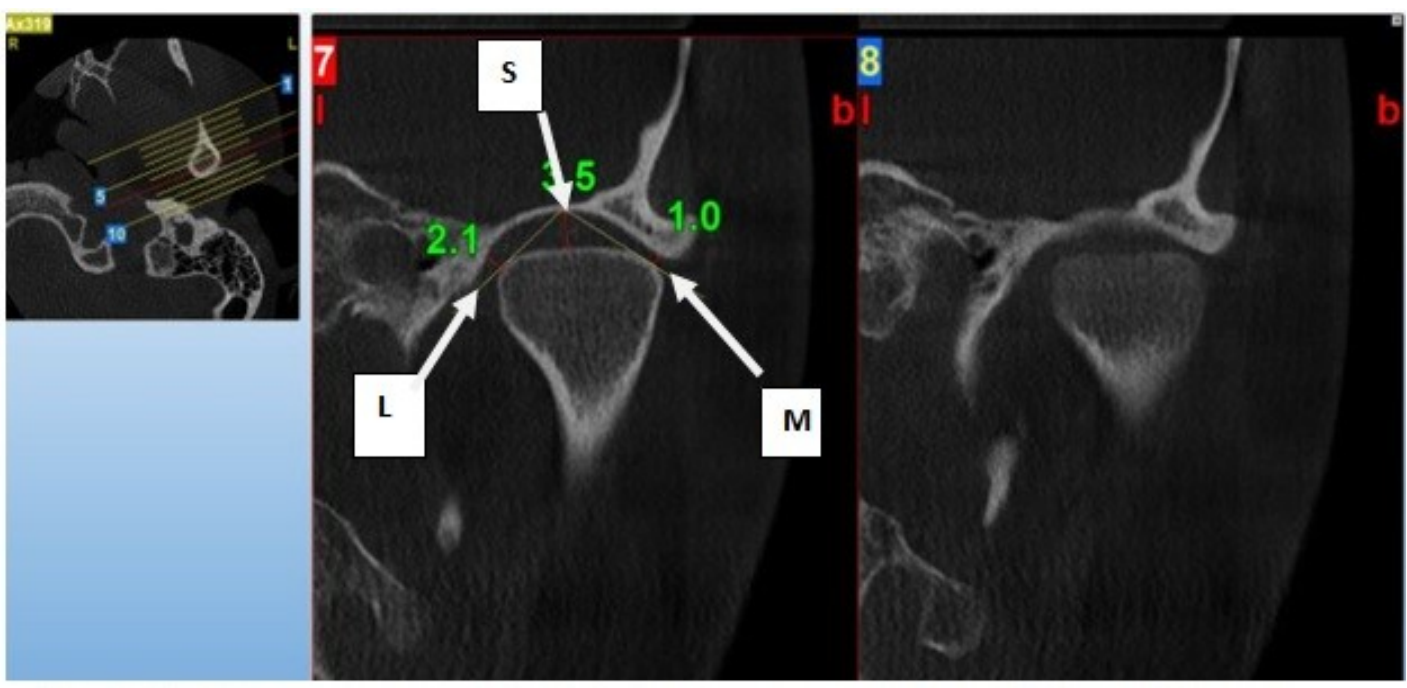

Figure 2: The measurement of joint spaces around condylar head in $\mathrm{mm}$ distance by CBCT, Medial joint space (M), Lateral joint space (L) and Superior joint Space (S). 


\section{Results}

Table 1 shows the mean of joint space of normal and affected side of 30 patients. The mean of affected side was generally less than normal side especially in anterior, superior and posterior joint spaces while in middle and the lateral joint space the differences is less in amount. Significant. differences were detected in anterior, superior and posterior joint spaces while in lateral and medial joint spaces no significant differences were detected. The analysis of joint spaces by CBCT is shown in Figure 3. The means of normal sides as shown in the Table 1 indicated that the normal joint spaces were between 2.3 to $3.2 \mathrm{~mm}$

Table 1: The mean value of joint spaces in normal and pathological (pain) side in all patients with statistical data analysis by T-test.

\begin{tabular}{lllllllll}
\hline & Type & $\mathbf{N}$ & Mean & Std. Deviation & $\begin{array}{l}\text { Std. Error } \\
\text { Mean }\end{array}$ & $\mathbf{t}$ & df & Sig.(p-value) \\
\hline Antspace & No pane & 30 & 2.487 & 0.729 & 0.133 & 4.32 & 58 & 0.000 \\
& Pane & 30 & 1.763 & 0.557 & 0.102 & & & \\
Supspace & No pane & 30 & 3.237 & 0.864 & 0.158 & 2.52 & 58 & 0.015 \\
& Pane & 30 & 2.717 & 0.730 & 0.133 & & & \\
Postspace & No pane & 30 & 2.367 & 0.552 & 0.101 & 3.08 & 58 & 0.003 \\
& Pane & 30 & 1.923 & 0.564 & 0.103 & & & \\
Medialspace & No pane & 30 & 2.720 & 0.705 & 0.129 & 0.27 & 58 & 0.790 \\
& Pane & 30 & 2.677 & 0.537 & 0.098 & & & \\
\multirow{2}{*}{ Lateralspace } & No pane & 30 & 2.377 & 0.783 & 0.143 & 1.61 & 58 & 0.113 \\
& Pane & 30 & 2.053 & 0.772 & 0.141 & & & \\
\hline
\end{tabular}

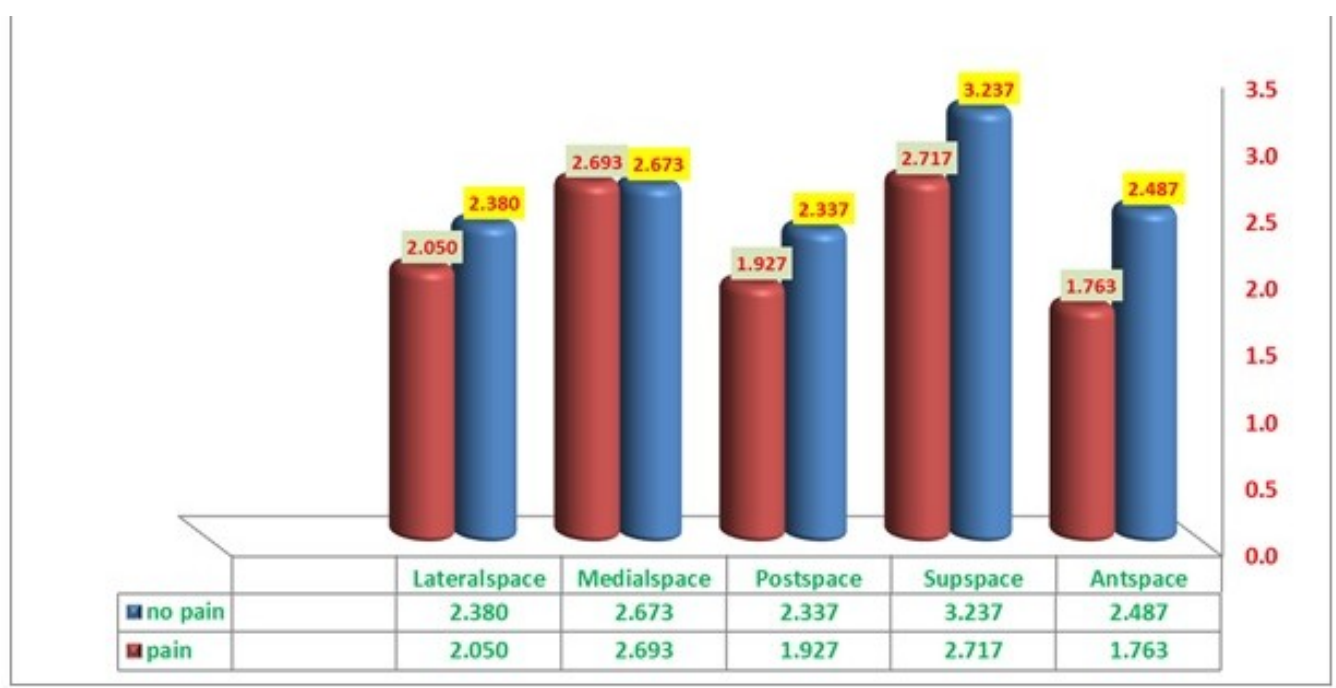

Figure 3: The mean value of joint spaces in normal and disease side of patients. 


\section{Discussion}

TMJ is considered as one of the difficult areas to evaluate by routine radiographs (panoramic radiography) and conventional plain radiographs (TMJ projections) because of super imposition of adjacent structures and its low sensitivity and accuracy for deeper structures. ${ }^{19}$ By development of CBCT which can provide three dimensions in imaging of TMJ area and it can produces reconstructed images with high diagnostic quality. ${ }^{16}$ TMJ space measurement and condylar relation is best analyzed by CBCT. This study showed that joint spaces in normal and diseased space side show significant differences at anterior and superior and posterior joint spaces. These differences may be due to the muscles spasm of the TMJ area in the diseases side. This result come in agreement with the other studies ${ }^{3,6,15}$ in which it was indicated that joint spaces may be changed in TMJ disorders. The other cause of this space changing may be attributed to disc problems which may relate to pain and joint space changing. This can be better evaluated by using MRI image for TMJ as this is indicated in some studies. $^{7,11,15}$ The result in this study showed that normal joint spaces were between 2.3 to 3.2 which is similar to another study done by Zahra ${ }^{14}$ and this is considered to be the normal requirement for joint space in normal function TMJ.

\section{Conclusion}

The use of CBCT for examination of TMJ space in patients with myofacial pain dysfunction syndrome gives a good diagnostic criterion for affected side. This study shows that there is a significant relation between TMJ spaces (anterior, superior and posterior) and myofacial pain in affected side as it was less than normal side. This can be considered one of indicators about the changes which can be seen in myofacial pain dysfunction syndrome in TMJ examination by CBCT.

\section{Conflicts of interest}

The author reports no conflicts of interest.

\section{References}

1. White S, Pharoah M. Oral Radiology Principles and interpretation. 1st ed. St. Louis, Mo.: Mosby/ Elsevier; 1987. P. 654-5.

2. Cawson R, Odell E. Cawson's essentials of oral pathology and oral medicine.1st ed. Edinburgh: Churchill Livingstone; 2008. P.192-3.

3. Burket L, Greenberg M, Glick M, Ship J. Burket's oral medicine. 1st ed. Hamilton, Ont.: BC Decker; 2008. P. 223-43.

4. Weinberg $L$. The role of stress, occlusion, and condyle position in TMJ dysfunction-pain. J Prosth Dentis 1983; 49(4):532-45.

5. Field E, Longman L, Tyldesley W. Tyldesley's Oral medicine. 1st ed. Oxford: Oxford University Press; 2003. P.196-7.

6. Palomo L, Palimo J. Cone beam Computed Tomography for diagnosis \& treatment planning in trauma cases. J Clin Dentis 2009; 53:717-27.

7. Chin L, Aker F, Zarrinnia K. The visco elastic properties of the human tempromandibular joint disc. J Oral Maxillofac Surg 1996; 54:315-8.

8. Okeson J. Management of tempromandibular disorders and occlusion. 1st ed. St. Louis, Mo.: Mosby; 2003. P.228-9.

9. Setton A, Zho W, Mow C. The Biphasic poro visco elastic behavior of articular cartilage: Role of the serface zone in governing the compressive behavior. J Biomech 1993; 26(4-5):581-92.

10. Wang R, Max C, Zhang W, Liu D. Investigation of tempromandibular Joint space of healthy adults by using cone beam computed tomography. Dent Research J 2007; 39(5):503-6.

11. Fushima K, Ballo L, Krebs M, Palla S. Analysis of the TMJ intra articular space variation: A non-invasive insight during mastication. Med Eng physic 2003; 25:181-90.

12. Bhuvana K, Mamatha N , Kumar V. Review Practice Guidelines of TMJ imaging by CBCT. J Oral Maxillofac Radiol 2013; 3(1):80-3.

13. Al-Ani Z ,Gray R , Stephen j,Philip D, and Annemarie G. Stabilzation splint therapy for the treatment-tempromandibular myofascial pain: Asystematic Review. JDent Educ 2005; 62 (11):1242-50.

14. Dalili Z, Khaki N, Kia S, Salamat F. Assessing joint space and condylar position in the people with normal function of temporomandibular joint with cone-beam computed tomography. Dent Research J 2012; 9(5):607-8.

15. S"umb"ull"u M, Cauglayan F, Akg"ul H, Yilmaz A. Radiological examination of the articular eminence morphology using cone beam CT. Dent Maxillofac Radiol 2012; 41(3):234-6.

16. Mirach A, Mukherji S. Cone beam CT of the head \& neck, part 2 : clinical applications Am J Neuroradiol 2009; 30:1285-92.

17. Scarfe W, Farman A, Sukovic P. Clinical applications of cone-beam computed tomography in dental practice. J Canad Dent Assoc 2006; 72 (1):573-6. 
Assessment of tempromandibular joint space ........

Zanco J. Med. Sci., Vol. 19, No. (1), 2015

http://dx.doi.org/10.15218/zjms.2015.0014

18. White S, Pharoah M. Oral radiology. 1st ed. St. Louis, Mo.: Mosby/Elsevier; 2009. P. 655-7.

19. Petersson A. what you can and can't see in TMJ imaging an over view related the RDL /TMD diagnostic system. J Oral Rehab 2010; 37: 771-8. 